\title{
Chapter 2 \\ The AgeCap Conceptual Framework for Research on Capability in Ageing
}

Therese Rydberg Sterner, Greta Häggblom-Kronlöf, and Pia Gudmundsson

\subsection{Theoretical Framework in Brief}

The overall vision of AgeCap is a society in which ageing is valued for its potential and older adults are respected - a society in which older people are viewed as resources. The research within our Centre originates from the perception that today's society is not optimal for promoting the health of older people. Our aim is to investigate and understand capability in ageing and related factors in order to fulfil our common goal of increasing the quality of life and societal participation of older people. While there are several ways to meet this challenge, AgeCap has chosen the capability approach in order to focus on a more health- and ability-related perspective, rather than on disease or disabilities.

The understanding of capability used within the centre is based on the work of the philosopher and economist Amartya Sen, described as the individual's ability to perform actions in order to reach goals he or she has reason to value (Sen, 2009). The capability approach focuses on what people are able to do and to be - their

T. Rydberg Sterner $(\bowtie) \cdot$ P. Gudmundsson

Neuropsychiatric Epidemiology Unit, Department of Psychiatry and Neurochemistry, Institute of Neuroscience and Physiology, Sahlgrenska Academy at the University of Gothenburg, Gothenburg, Sweden

Centre for Ageing and Health - AgeCap, University of Gothenburg,

Gothenburg, Sweden

e-mail: therese.rydberg.sterner@gu.se; pia.gudmundsson@neuro.gu.se

G. Häggblom-Kronlöf

Institute of Neuroscience and Physiology, Department of Health and Rehabilitation, Sahlgrenska Academy at the University if Gothenburg, Gothenburg, Sweden

Centre for Ageing and Health - AgeCap, University of Gothenburg,

Gothenburg, Sweden

e-mail: greta.haggblom-hronlof@neuro.gu.se 
capabilities - and on their freedom of choice to perform those actions. The capability approach has been further developed by philosopher Martha Nussbaum, who focuses on justice and human rights in her theory and defends the importance of the capability approach in the context of welfare and quality of life (Nussbaum, 1997). Both Nussbaum and Sen argue that the capability approach needs to be combined with a human rights perspective. As such, every older person has the right to be able to perform actions in order to reach their own goals of value. In the model and graphic illustration of the conceptual framework of capability outlined in this chapter (see Figs. 2.1 and 2.2), justice is therefore the platform upon which the approach rests. The graphic illustration is also inspired by the work of Ingrid Robeyns, who has focused on how to apply the capability approach in practice in research settings (Robeyns, 2005).

\subsection{Why a Theoretical Framework?}

AgeCap's multidisciplinary setting was an opportunity to adopt the capability approach within our research. Nevertheless, this multidisciplinary approach also created challenges in establishing a common definition of capability, and how to apply the concept in collaborations across several different research fields. When AgeCap was formed in 2013, the need for a common conceptual foundation quickly became evident. It was also proposed during the first meeting with our Advisory Board in the autumn of 2014 that a conceptual framework laying out our shared view of capability in ageing needed to be developed. Thus, the purpose of having a common conceptual framework and graphic illustration was to facilitate the implementation of the capability approach in our research setting.

Based on the above-described circumstances, 'capability seminars' involving researchers from all the collaborations within AgeCap were initiated during 2014. In addition, each research group organised internal discussions about the concept of capability based on pre-selected literature from different perspectives, which were summarised and utilised as a foundation for developing the framework. After approval from the AgeCap Steering Committee, members of the Communication Group became responsible for leading this process, with continuing discussions with the Steering Committee, Principal Investigators and other researchers within AgeCap. The final version of the capability framework was completed in March 2016 and communicated to all members of AgeCap.

\subsection{Central Concepts in the AgeCap Capability Framework}

The content and core characteristics of the AgeCap capability framework are based on the work of Amartya Sen (2009), Martha Nussbaum (1997) and, primarily, the theoretical model published by Ingrid Robeyns (2005). The core characteristics are 


\begin{tabular}{|c|c|c|c|}
\hline \multicolumn{2}{|c|}{$\begin{array}{l}\text { CAPABILITY SET } \\
\text { - the needed conditions of available resources and conversion factors, to perform } \\
\text { actions in order to reach goals of value, are available. }\end{array}$} & \multirow[t]{2}{*}{$\begin{array}{l}\text { FREEDOM OF } \\
\text { CHOICE }\end{array}$} & \multirow[t]{2}{*}{$\begin{array}{l}\text { GOALS OF } \\
\text { VALUE }\end{array}$} \\
\hline AVAILABLE RESOURCES & CONVERSION FACTORS & & \\
\hline $\begin{array}{l}\text { The older person's available resources at } \\
\text { different levels (micro, meso, macro) in } \\
\text { relation with effects of time period and the } \\
\text { person's age, and birth cohort. }\end{array}$ & $\begin{array}{l}\text { The older person's } \\
\text { ability to convert } \\
\text { available resources } \\
\text { into the goal that he } \\
\text { or she has reason } \\
\text { to value. }\end{array}$ & $\begin{array}{l}\text { The older person's } \\
\text { genuine opportunity } \\
\text { and freedom to } \\
\text { realize the goal that } \\
\text { he or she has reason } \\
\text { to value. }\end{array}$ & $\begin{array}{l}\text { The older } \\
\text { person's } \\
\text { achieved goals } \\
\text { that he or she } \\
\text { has reason to } \\
\text { value. }\end{array}$ \\
\hline USTICE & & & \\
\hline
\end{tabular}

Fig. 2.1 A conceptual model of the capability framework in AgeCap

presented below. All concepts in the framework are related to each other by dynamic and complex interactions, and various factors can be classified as different concepts in the graphical illustration below, depending on each specific situation. Furthermore, although the description and examples below focus on an older person, the capability approach may also be applied to groups of people, organisations or systems, depending on the field of research.

\subsubsection{Capability Set}

What an individual can do and prefers to do is dependent on actual available resources and existing constraints. The combination of macro-, meso- and microlevels, as well as time-trend circumstances, constitute the basis for an individual's capability set, i.e., what a person actually can or cannot do (a combination of available resources and conversion factors). Having a full capability set entails that the necessary conditions for reaching the valued goal are available. There is an overlap between available resources and conversion factors, which generates a challenge to separate them. For example, health literacy (the degree to which individuals have the capacity to obtain, process and understand the basic health information and services needed to make appropriate health decisions) could be both a resource (e.g. being able to understand the information) and a conversion factor (e.g. being able to make appropriate health decisions). 


\subsubsection{Available Resources}

A person's resources throughout the life course are available at several societal levels (i.e. the macro-, meso- and micro-levels). Resources at the macro-level refer to laws and regulations that affect pensions, social security, norms about ageing, the labour market, healthcare and its related organisations and costs. At the meso-level, we find the configurations within which daily life is embedded, e.g. family life, relationships, social networks, meetings with caring facilities, caring obligations and, for the young-old, the workplace. The micro-level contains a whole range of accumulated features that may enable or limit a person's capability. Resources at the micro-level include factors such as genetic predispositions, personality, physical, mental and social health, lifestyle, cognitive functioning, neurobiology, psychosocial and socioeconomic factors, preferences and education. The balance and relative importance of the resources at each societal level vary between individuals, and are affected by our age, within which birth cohort we were born and during which time period we live.

\subsubsection{Conversion Factors}

A person's conversion factors consist of their ability to actually convert available resources into a goal that he or she has reason to value. The ability to use and adapt the available resources exists in everyday life and is divided into three levels: personal, social and environmental. Personal conversion factors include, for instance, metabolism, health literacy, physical health status etc. The social conversion factors include societal mechanisms such as discriminatory circumstances like social class, hierarchies or power structures between the sexes etc. Environmental conversion factors include climate or geographical location etc. In order to reach a goal of value, a person must first be able to recognise the necessary resources and then have the ability to use them.

\subsubsection{Freedom of Choice}

Freedom of choice refers to a person's everyday choices when performing actions in order to reach their goal of value. Martha Nussbaum explained this by saying 'once the stage is set, the choice is up to them' (Nussbaum, 1997: 290). 'The stage' here refers to the person's capability set. This means that, when all the prerequisites are in place, the individual always has the freedom to choose whether or not to utilise their capability set (i.e. their available resources and conversion factors) in order to reach the goal in question. 


\subsubsection{Goals of Value - Personal Goals}

The goals that an individual has reason to value can be defined as 'goals of value'. These goals are unique to each person and should be independent of the person's functional level or health status. However, there is a challenge in that individuals adapt their goals of value to their current life situation, meaning that expectations may affect the choice of goals.

\subsubsection{Justice - A Person's Right to Achieve Goals of Value}

As stated in the background section above, both Nussbaum and Sen argue that the capability approach needs to be combined with a focus on human rights. This is applied in AgeCap through an overarching principle that every person has the right to be able to perform actions in order to achieve their own goals of value. Nussbaum claims that capabilities are the political goal but, as stated earlier in this chapter, every person must then be free to decide whether or not to use the provided tools to achieve a certain goal. People are not to be viewed as passive recipients, and the important inclusion of the keyword 'choice' in the capability approach respects their freedom (Nussbaum, 1997). Justice in the capability approach considers both the right to achieve goals, and also the right to freedom of choice. This freedom to choose is dependent on determinants and different arrangements within a society; for example, facilities within the healthcare system. Furthermore, sociocultural values and traditions that appear in different unique settings can be either 'freedom facilitators' or 'freedom inhibitors', which directly or indirectly affect the person's ability to choose and to achieve their goals of value.

\subsection{A Graphical Illustration of the AgeCap Capability Approach}

To facilitate the application of the capability approach within our research setting, and to make it more accessible to different target groups within society, the AgeCap Steering Committee decided that a graphic illustration of the AgeCap framework of capability should be created in collaboration with graphic designers and the Sahlgrenska Academy at the University of Gothenburg. 


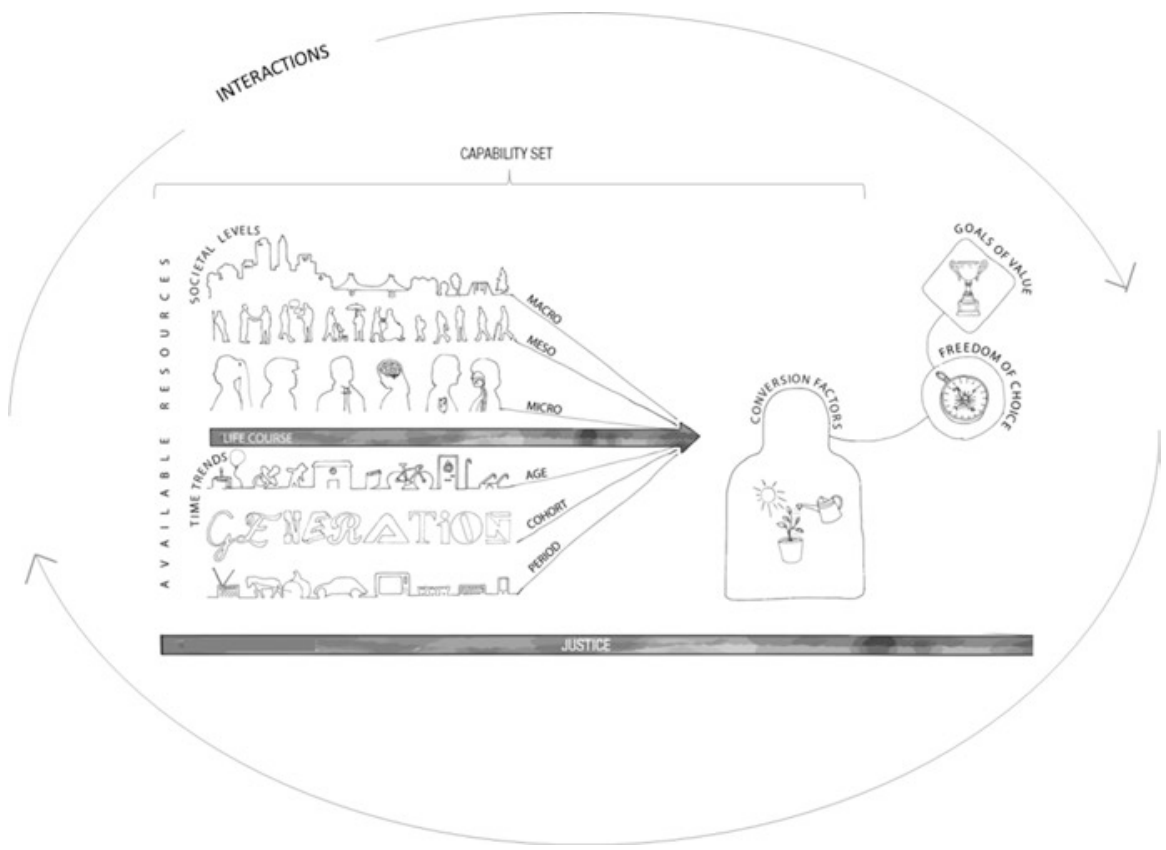

Fig. 2.2 A graphic illustration of the AgeCap capability approach

\subsection{Challenges and Reflections}

The development of a conceptual framework within a broad, multidisciplinary research centre such as AgeCap entailed several challenges that required reflection. Although it was of great importance to create a common foundation and to share a common view of the key concept of capability, there were also great difficulties involved in making this view applicable to all research fields. The framework has the aim of explaining and simplifying the concept of capability, yet retaining an awareness of the challenges related to our multidisciplinary setting. Thus, the conceptual framework was developed mainly to serve as a platform for researchers to use in whatever way they found most relevant from their own perspective.

\subsubsection{How Could the Framework Be Applied?}

The framework was developed to guide discussions regarding research on capability in ageing, and to understand the complex associations between the different factors that influence ageing and health. Is it possible or even relevant to apply the AgeCap capability approach in our research? And if so, how could it be done? Must the concept of capability be measured and included as a core factor in our research 
project from the beginning, or could it merely be applied as an overarching perspective that permeates projects from method to discussion? The most reasonable answer ought to be: 'it depends'. It depends on the research question, the research setting, the field and the interests of the individual researcher.

The main purpose of AgeCap is to investigate capability in ageing as demonstrated and seen in the following chapters of this book. In some research projects, the inclusion of the concept is very straightforward and obvious, while in others the connection between the investigated factors and capability is less clear. Different research programmes, as well as specific collaborations and research questions, focus on various different areas and levels of the theoretical framework of capability. For example, at the micro-level, genetic, cognitive and behavioural factors may be evaluated, while at the macro-level researchers might be investigating factors related to the law, ageism and culture. However, all projects within AgeCap aim to fulfil our common goal - to enable and enhance capability in ageing and thereby to contribute to increased quality of life and societal participation for older people.

The graphic illustration may also be applied outside the research community in order to make the general public feel more included in the research that is planned and performed within AgeCap. It is an endeavour to make our theoretical framework more accessible so as to dismantle the wall between researchers, older people and the general public.

\subsubsection{What Is Freedom of Choice?}

What constitutes a 'free' choice? How can we know if a person has the genuine opportunity and freedom to realise a goal that he or she has reason to value? Is 'freedom of choice' the same for a person with largely preserved cognitive abilities as it is for a person affected by dementia? These questions are important to keep in mind and discuss in relation to the capability approach.

\subsubsection{Goals of Value - Subjective or Objective?}

A person may not think they have the required abilities to achieve a certain goal, and may therefore exclude it as a goal worth striving for. Is this important to consider? Do we all have the same mindset towards reachable goals, or is it more realistic that each person defines their goals in line with their expectations and current life situation? Who decides which goals are valuable or not? Is it up to the researcher, or the individual? This question is a dividing line between Sen and Nussbaum - whether Nussbaum's 'list' (see a simplified version in Box 2.1) should be applied or not. This list was created by Nussbaum with the aim of deciding upon ten morally relevant capabilities and goals of value (Nussbaum, 1997). Sen criticises this list and emphasises that all capabilities and goals of value are morally relevant, and that a 


\section{Box 2.1: Nussbaum's List in Brief. The Complete List Can Be Found Elsewhere (Nussbaum, 1997)}

Being able to live a life of normal length

Having physical health, reproductive health, food and shelter

Being able to move freely and safely, not being exposed to violence, having sexual freedom

Being able to use the senses, imagination, thought, education, freedom of speech

Being able to have attachments to things and people outside ourselves, to feel devotion, love, grief, desire, gratitude and anger

Being able to form a conception of the good and to engage in critical reflection about the planning of one's life

Affiliation, living with others, being treated with respect and dignity, absence of discrimination due to ethnicity, sexual orientation, religion etc.

Being able to live with concern for and in relation to animals, plants and the world of nature

Being able to laugh, play and enjoy recreational activities

Political and material control over one's environment, political participation, having the right to employment

goal of value can only be expressed and chosen by a person themselves (Sen, 2005). On the other hand, Nussbaum criticises Sen for not having a list, because she thinks that considering justice demands making a distinction between morally relevant and non-relevant capabilities (Nussbaum, 1997). However, it can be very difficult to distinguish a clear line between goals, available resources and conversion factors. Thus, what is the difference between subjective and objective goals of value? Subjective goals of value are retrieved from the person, e.g. by asking an open question, such as: 'what is most important to you?' or 'which aspects of life mean the most to you?' Objective goals of value are predefined, and are not chosen by the person. Two examples of objective goals of value are Nussbaum's list and the ICECAP-O questionnaire, which will be addressed in Chap. 3.

\subsection{Summary and Future Directions}

The conceptual framework of capability and the graphic illustration introduced in this chapter were developed as an endeavour to meet the pronounced need for a shared platform related to capability in ageing within AgeCap, and to make our theoretical framework more accessible to the general public. The framework is based on the capability approach that was developed by Sen, Nussbaum and Robeyns (Sen, 2009; Nussbaum, 1997; Robeyns, 2005), and adapted for the multidisciplinary ageing context of AgeCap. The research questions within AgeCap 
typically exist at several levels and within different parts of the framework. Due to the difficulty of considering the entire capability approach in each specific project, some research projects will utilise the theoretical framework more than others. Each piece of enhanced knowledge related to capability that is produced by AgeCap collaborations will thus play an important role in our research context.

The conceptual framework of capability represents an indicative starting point for investigating capability in ageing, and to guide the reasoning and discussions within our multidisciplinary setting. Furthermore, it may facilitate our understanding of the complex associations between ageing and health within our many research fields. AgeCap researchers are encouraged to use the framework in whichever way they find relevant from their own perspective in order to achieve our joint goal of increasing the quality of life and societal participation of older adults.

\section{References}

Nussbaum, M. C. (1997). Capabilities and human rights. Fordham Law Review, 66(2), 273-300. Robeyns, I. (2005). The capability approach: A theoretical survey. Journal of Human Development, 6(1), 93-114.

Sen, A. (2005). Human rights and capabilities. Journal of Human Development, 6(2), 151-166. Sen, A. (2009). The idea of justice. Belknap Press of Harvard University Press.

Open Access This chapter is licensed under the terms of the Creative Commons Attribution 4.0 International License (http://creativecommons.org/licenses/by/4.0/), which permits use, sharing, adaptation, distribution and reproduction in any medium or format, as long as you give appropriate credit to the original author(s) and the source, provide a link to the Creative Commons license and indicate if changes were made.

The images or other third party material in this chapter are included in the chapter's Creative Commons license, unless indicated otherwise in a credit line to the material. If material is not included in the chapter's Creative Commons license and your intended use is not permitted by statutory regulation or exceeds the permitted use, you will need to obtain permission directly from the copyright holder. 